\title{
Application Article \\ Compact Circular/Linear Polarization Dual-Band Prime-Focus Feed for Space Communication
}

\author{
Rastislav Galuscak, Pavel Hazdra, and Milos Mazanek \\ Department of Electromagnetic Field, Faculty of Electrical Engineering, Czech Technical University in Prague, Technicka 2, \\ 16627 Prague, Czech Republic \\ Correspondence should be addressed to Pavel Hazdra, hazdrap@fel.cvut.cz
}

Received 2 January 2012; Revised 7 April 2012; Accepted 10 April 2012

Academic Editor: Hamsakutty Vettikalladi

Copyright ( $\odot 2012$ Rastislav Galuscak et al. This is an open access article distributed under the Creative Commons Attribution License, which permits unrestricted use, distribution, and reproduction in any medium, provided the original work is properly cited.

We propose a novel, compact, prime-focus antenna feed for space communication. The feed requires full-wave simulator optimization for a given parabolic reflector and is designed to operate simultaneously on two bands, offering LHC/RHC polarizations for the $13 \mathrm{~cm}$ band and $\mathrm{V} / \mathrm{H}$ polarizations for the $70 \mathrm{~cm}$ band. With performance results confirmed by measurement, it has been verified in practice that this compact feed is suitable for use in a low-noise Earth-Moon-Earth communication link.

\section{Introduction}

Amateur radio Moon Bounce, EME (Earth-Moon-Earth), communication is a very technically demanding discipline [1]. Usually, high-gain reflector antennas are used, but they require appropriate prime-focus feeds designed mainly for low-noise operation [1].

EME communications do not require simultaneous multiband operation; so, to change the working band, a station operator has enough time to exchange prime-focus feeds.

Additionally, the antenna gain depends on the diameter of the dish reflector, which is very often limited by space and operating cost requirements. For users, it is very important to squeeze every possible tenth of a $\mathrm{dB}$ from their antennas, recognizing the inherent lack of adequate gain. This requirement is in contrast to the effectiveness of multiband reflector antennas whose efficiency is usually lower than that of monoband antennas due to the compromised designs of their feeds.

Dual-band or multiband prime-focus feeds are used only by stations equipped with electrically large and especially physically large-size reflectors, where replacement of the prime feed is mechanically very demanding, expensive, or difficult to implement.
A description of a $10 \mathrm{~m}$ dish antenna's dual-band primary feed for the $70 / 23 \mathrm{~cm}$ bands was published by Doug McArthur [2]. McArthur's feed consisted of a dual-mode waveguide feed for $23 \mathrm{~cm}$ surrounded by four dipoles for $70 \mathrm{~cm}$. See Figure 1.

Since the dipoles' impedance is about 105 ohms, they must be impedance-matched by employing feed lines of $\lambda / 4$ length with $72.5 \mathrm{ohm}$ impedance. This design also requires isolating the dipoles from their ground plane, see Figure 2.

This solution introduces unwanted and unpredictable impedance behavior, especially when the feed is mounted onto a dish. However this design was successfully fabricated by several operators worldwide [2]. Unfortunately, measured radiation patterns were not disclosed by the author. Similar solution consisting of waveguide and dipoles has been recently reported for $\mathrm{X} / \mathrm{Ka}$ bands [3].

The proposed design of a dual-band prime-focus feed utilizing butterfly-shaped dipoles and a ground plane subreflector equipped with a choke can be regarded as a completely novel approach for coverage of EME $70 / 13 \mathrm{~cm}$ bands.

This paper describes a compact, dual-band feed (70/ $13 \mathrm{~cm}-432 / 2320 \mathrm{MHz}$ ) intended for a parabolic reflector with a diameter of $6.4 \mathrm{~m}$ and $\mathrm{f} / \mathrm{D}$ ratio of 0.4 . Horizontal and vertical polarizations are available on the $432 \mathrm{MHz}$ band. The 


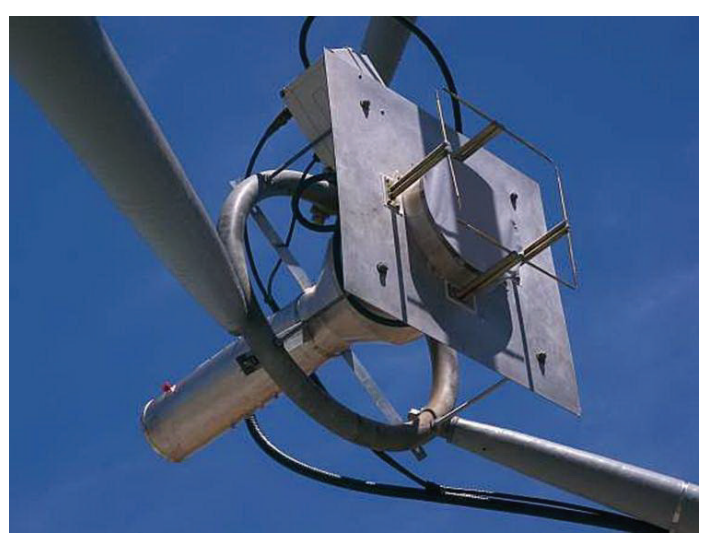

FIgUre 1: Doug McArthur's feed for $70 / 23 \mathrm{~cm}$ bands.

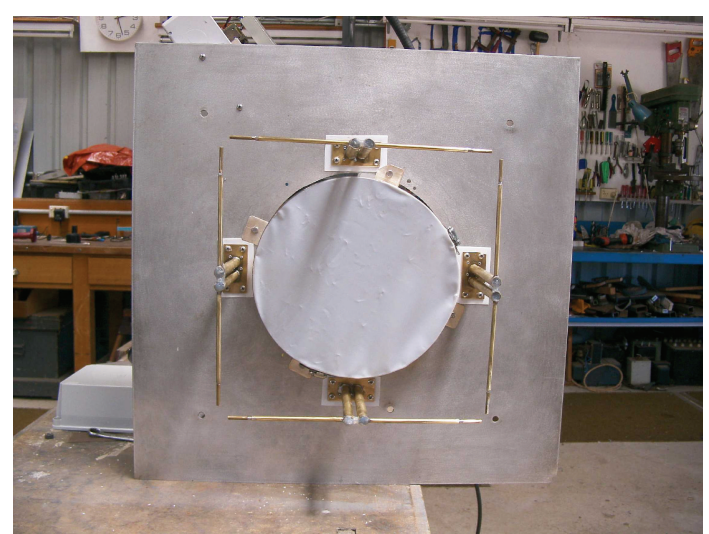

Figure 2: Front view of Doug McArthur's feed.

$2320 \mathrm{MHz}$ band feed can operate with both right and lefthand circular polarization. Hence, this compact feed offers dual polarization operation at both bands.

\section{Requirements for Dual-Band Prime-Focus Feed}

Above considerations dictate the following requirements for the dual-band feed:

(1) high gain in antenna assembly—minimal blockage of reflector;

(2) low noise—edge taper about $15 \mathrm{~dB}$;

(3) low backward radiation;

(4) RHC- and LHC-polarization capability with good axial ratio for $2320 \mathrm{MHz}(13 \mathrm{~cm}$ band);

(5) vertical and horizontal polarization for $432 \mathrm{MHz}$ $(70 \mathrm{~cm})$ band;

(6) able to handle high power, up to $3 \mathrm{~kW}$ with very good impedance match;

(7) low weight $<7 \mathrm{Kg}$ (in order to avoid mechanically distorting the shape of the parabolic reflector).

It should be emphasized that the feed needs not to be broadband since, for the EME purposes, the following

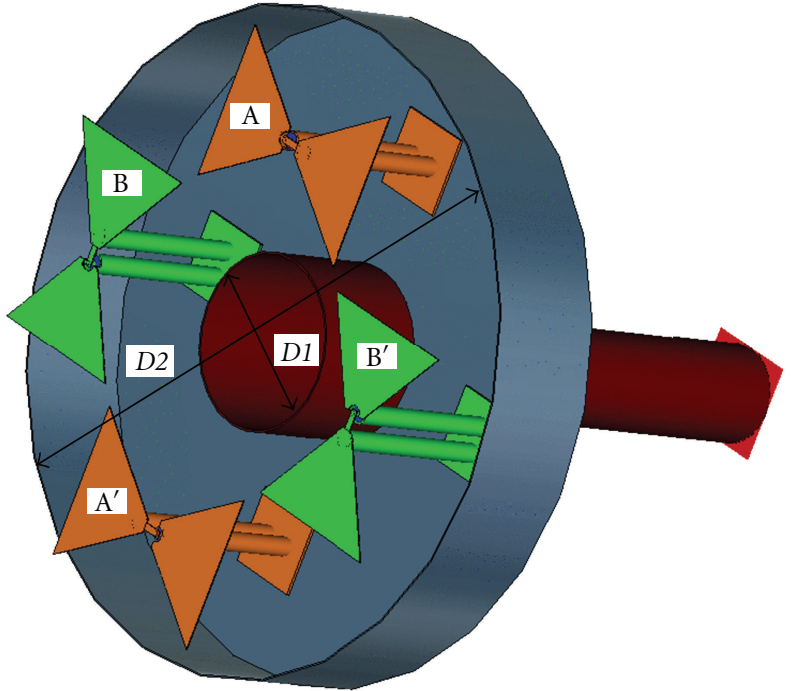

FIGURE 3: Layout of the dual-band feed, overall view.

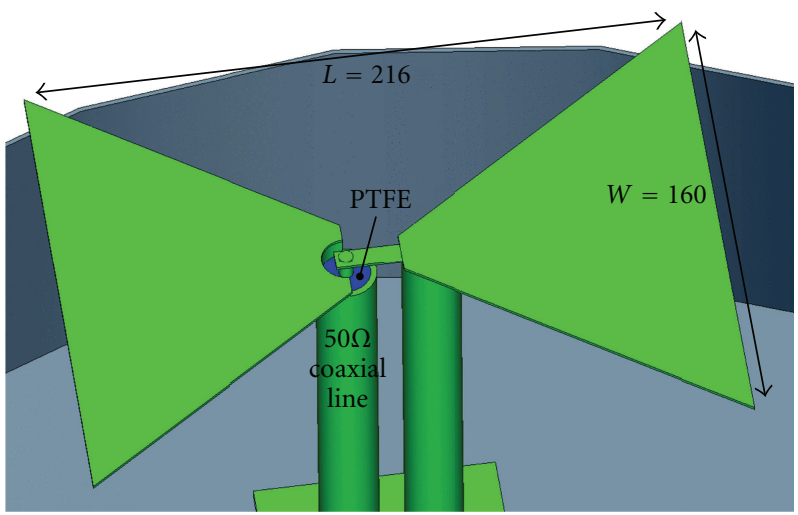

FIgURE 4: Detailed view of dipole feed.

frequencies are used: $432.050 \mathrm{MHz} \pm 50 \mathrm{kHz}$ on $70 \mathrm{~cm}$ and two frequencies $2304.050 \mathrm{MHz} \pm 50 \mathrm{kHz} / 2320.050 \mathrm{MHz} \pm$ $50 \mathrm{kHz}$ on $13 \mathrm{~cm}$ band.

\section{Design Concepts}

The proposed 6-port feed consists of two independent radiating systems described below-see Figure 3. Septum polarizer design was performed by MICIAN [4] software. All other simulations were performed by CST Microwave Studio software [5].

3.1. $432 \mathrm{MHz}(70 \mathrm{~cm})$ Band. The $432 \mathrm{MHz}$ feed is composed of two pairs of opposing bow-tie dipoles (A- $\mathrm{A}^{\prime}, \mathrm{B}-$ $\left.\mathrm{B}^{\prime}\right)$ responsible for vertical/horizontal polarization. These symmetrical dipoles are placed approximately $\lambda / 4$ above a circular ground plane. The dipoles are fed by $50 \Omega$ coaxial lines which are designed to mechanically and electrically match to $7 / 16^{\prime \prime}$ DIN style connectors, located on the bottom side of the ground plane, that are filled with PTFE to handle very high power. No impedance transformation 

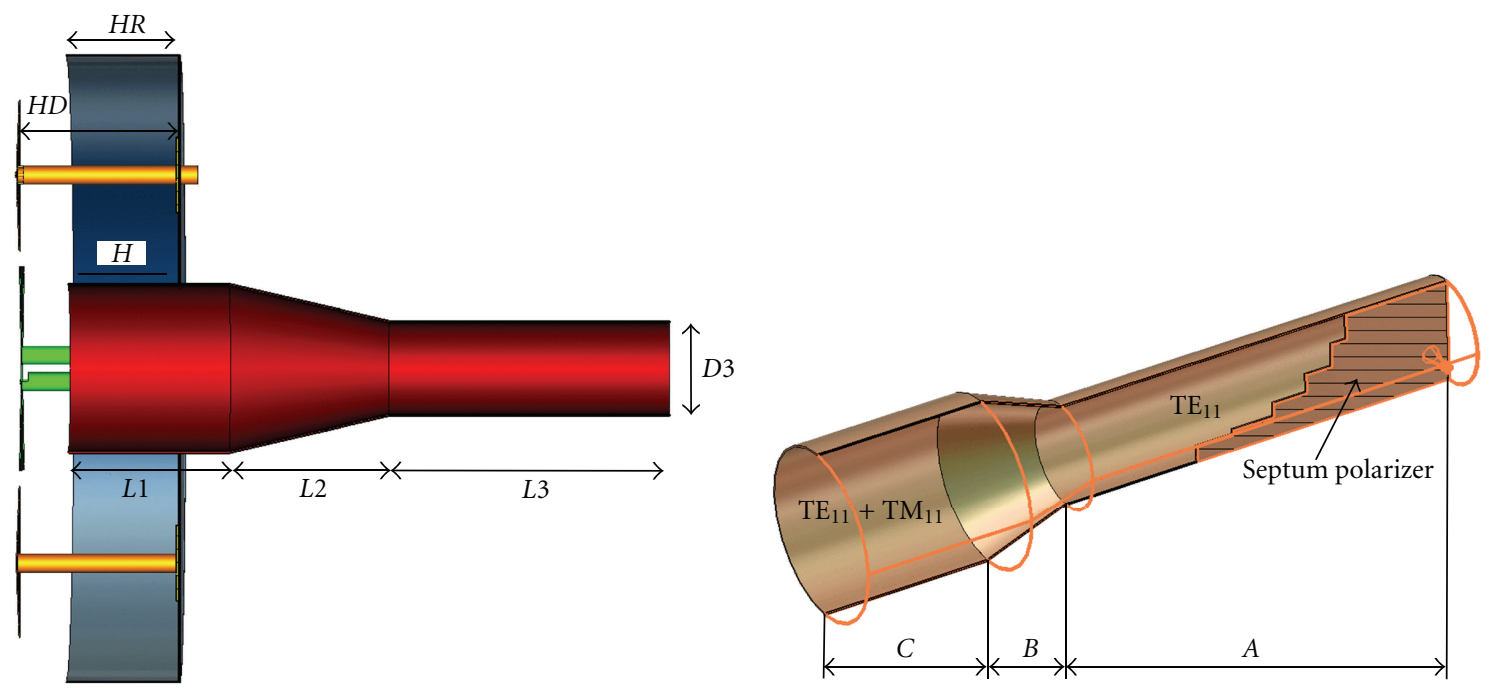

FIGURE 5: Layout of the dual-band feed, longitudinal cut (left) and internal view of the dual-mode horn equipped with five-step septum polarizer (right).

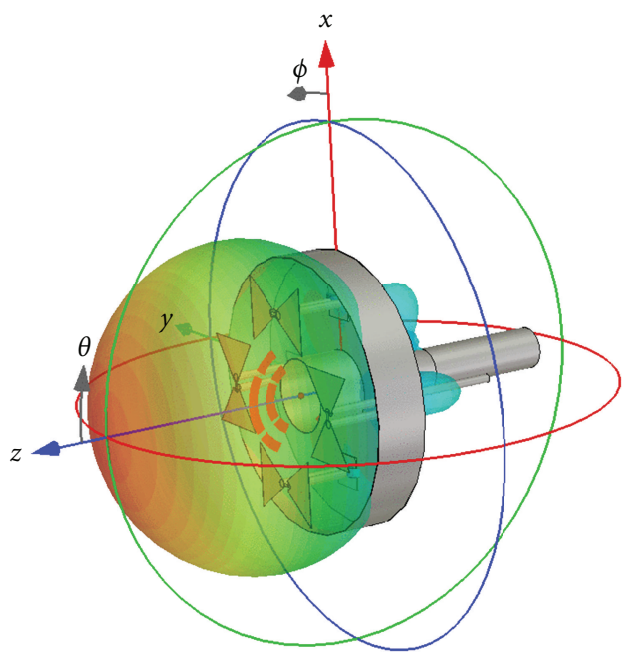

(a)
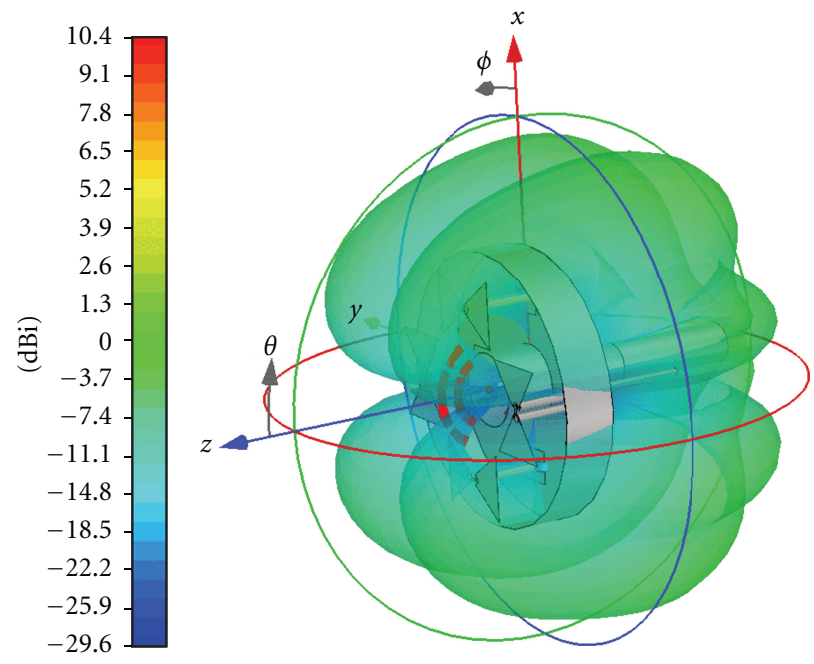

(b)

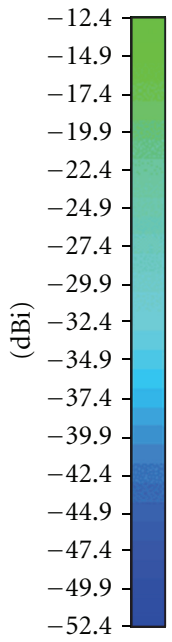

FIGURE 6: 3D radiation pattern at $432 \mathrm{MHz}$; copolarization (a) and cross-polarization (b). between connectors and dipoles is required (Figure 4). This arrangement allows direct grounding of the connectors to the ground plane with four screw fasteners. Symmetry is maintained with the outer shell of carrier pipes, which function as a sleeve balun $[6,7]$. For all polarization states, each pair of dipoles is excited by an external $3 \mathrm{~dB}$ Wilkinson power divider and 180 degree phase shifter, since dipole feed orientation is swapped in order to improve radiation pattern symmetry and minimize the supply line lengths.

3.2. $2320 \mathrm{MHz}(13 \mathrm{~cm})$ Band. The $2320 \mathrm{MHz}$ dual-port (LHC/RHC) feed is based on our previous research work dealing with septum polarizers [8-10], see also [11, 12]. Using CST software simulation, we found that conversion to circular polarization using a 5-step septum occurs at virtually $100 \%$ efficiency [9]. To obtain good pattern symmetry, suppression of side lobes, and separation of crosspolarization, a dual-mode (HE11) Potter-style horn [13-15] equipped with a septum polarizer has been chosen [15]see Figure 5. The transition between coaxial feed line and waveguide is achieved by using conical probes [9]. The circular ground plane functionally performs as a choke [16] having diameter D2 and height of rim HR. The choke effect is to slightly modify the Potter horn's radiation pattern causing a small decrease in the feed boresight, thus providing a slight performance improvement in our prime-focus feedconfigured antenna $[1,10]$. The ground plane provides for placement of the $432 \mathrm{MHz}$ dipoles as well.

Main design dimensions of the proposed feed are summarized in Table $1 ; \lambda_{432}$ and $\lambda_{2320}$ indicate wavelengths at center of respective band. 


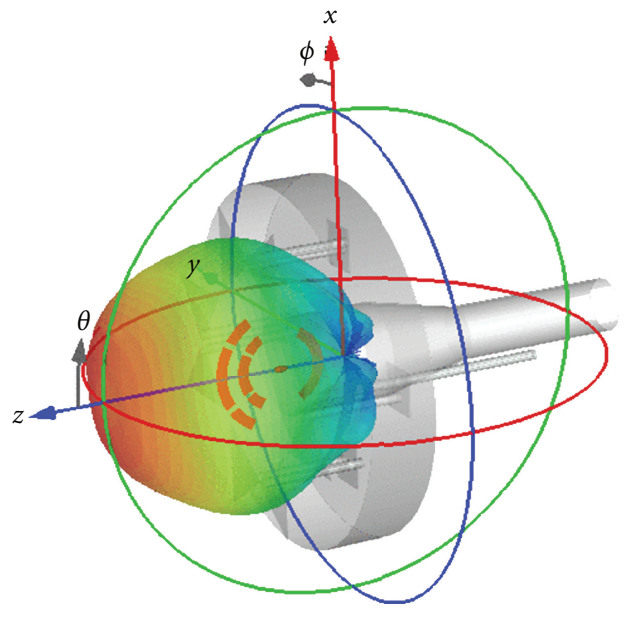

(a)
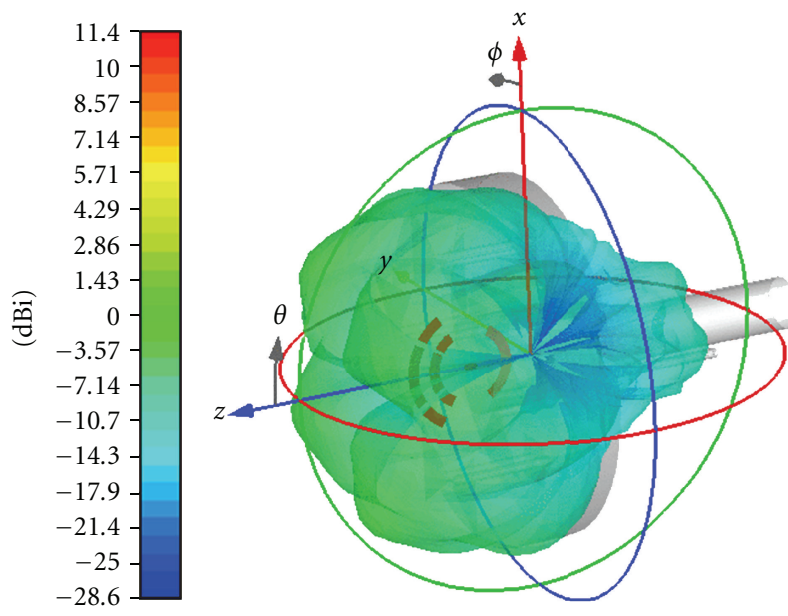

(b)

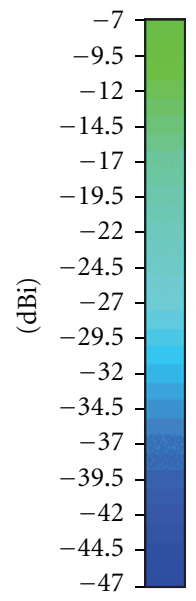

FIGURE 7: 3D radiation pattern at $2320 \mathrm{MHz}$; copolarization (a) and cross-polarization (b).

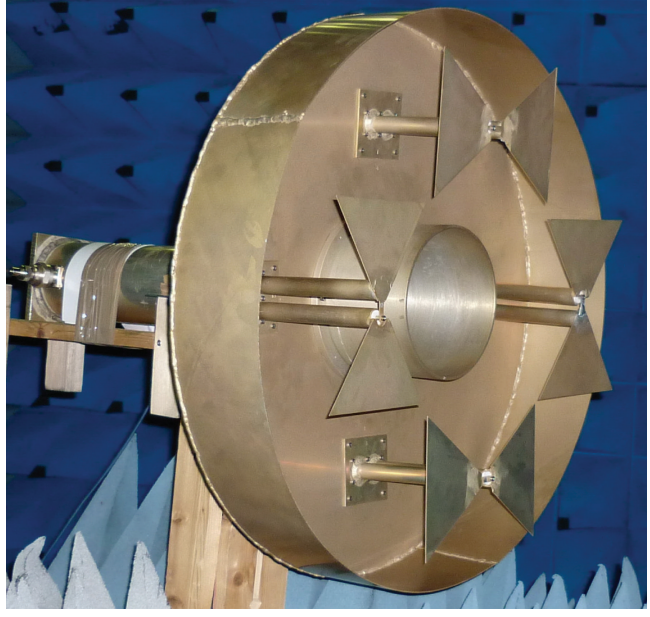

(a)

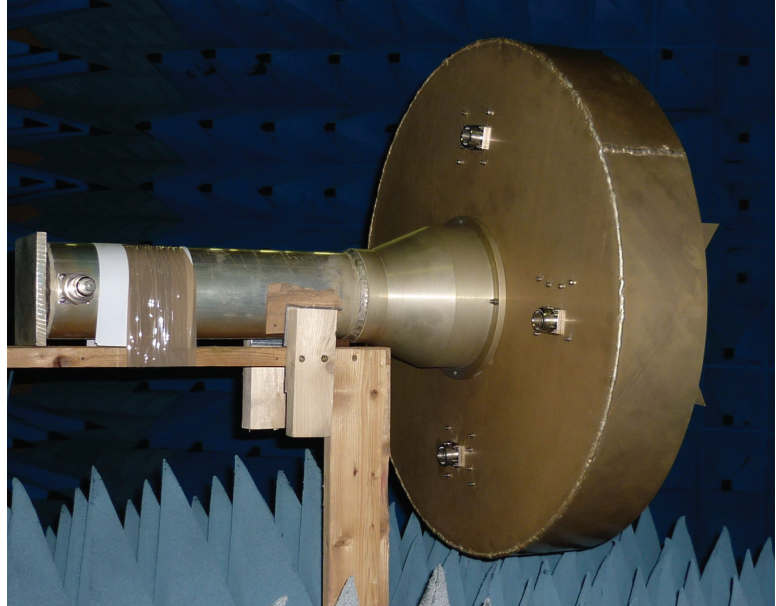

(b)

FIgURE 8: Feed prototype at the ERA anechoic chamber.

Very important is distance $H=123 \mathrm{~mm}$, that is, phase center position of the $2320 \mathrm{MHz}$ feed above the ground plane. It was designed to achieve flush positions for both phase centers.

\section{Results}

4.1. Simulated 3D Radiation Patterns. 3D radiation patterns from CST are shown in Figure 6 for $432 \mathrm{MHz}$ and Figure 7 for $2320 \mathrm{MHz}$. The symmetric patterns show low crosspolarization for both bands. Note the location of the phase centers (red points). For both the $432 \mathrm{MHz}$ and $2320 \mathrm{MHz}$ bands, the calculated phase centers are located $\pm 1 \mathrm{~mm}$ at the aperture plane (dimension HR).

A feed prototype (Figures 8 and 9) was fabricated from aluminum alloy and was measured in the anechoic chamber at ERA company [17]. The feed's weight is about $5 \mathrm{~kg}$.
4.2. Measured Radiation Pattern for $432 \mathrm{MHz}$. Since vertical and horizontal polarization pattern symmetry is excellent, the measured radiation pattern cut of $\mathrm{H}$ plane horizontal polarization is identical to the cut of E plane vertical polarization and vice versa. See Figure 10 for both polarization states. Note the very low cross-polarization level at the main lobe (suppression $<-25 \mathrm{~dB}$ ).

4.3. Measured Radiation Pattern for $2320 \mathrm{MHz}$. Measurement of only one polarization state (RHC) was performed with and without the $432 \mathrm{MHz}$ section acting as a choke (Figure 11). Its effect may be seen as a slight decrease in the main lobe, reducing blockage effects and improving the overall efficiency. However, the choke subtly increases backward radiation. The simulated Axial Ratio (AR) parameter is better than $0.1 \mathrm{~dB}$ in the boresight direction. No special measurement of AR has been performed, since our previous 


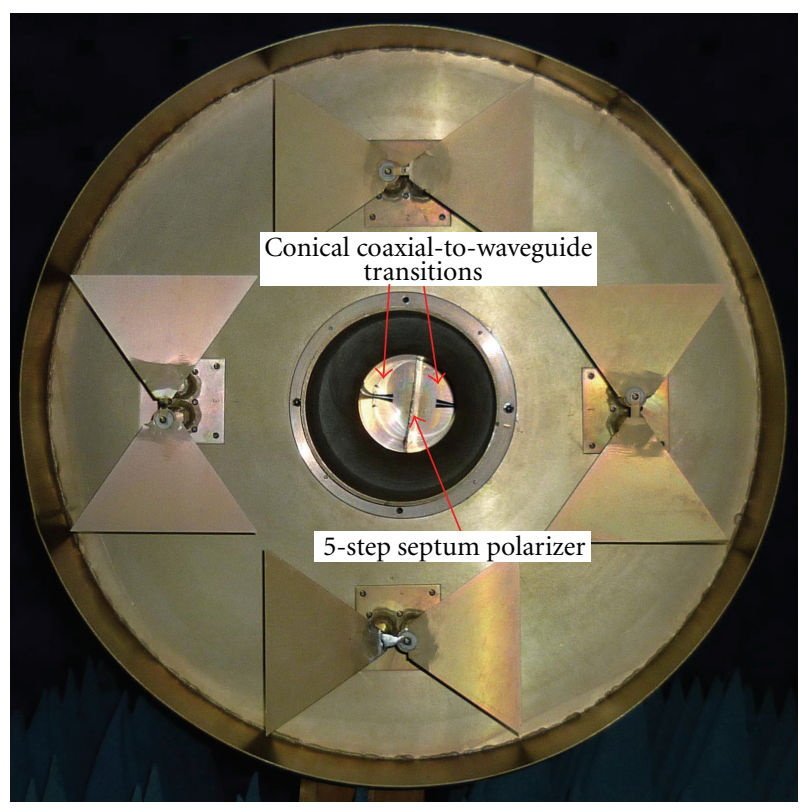

FIGURE 9: Feed prototype at the ERA anechoic chamber, front view (note $2320 \mathrm{MHz}$ section).

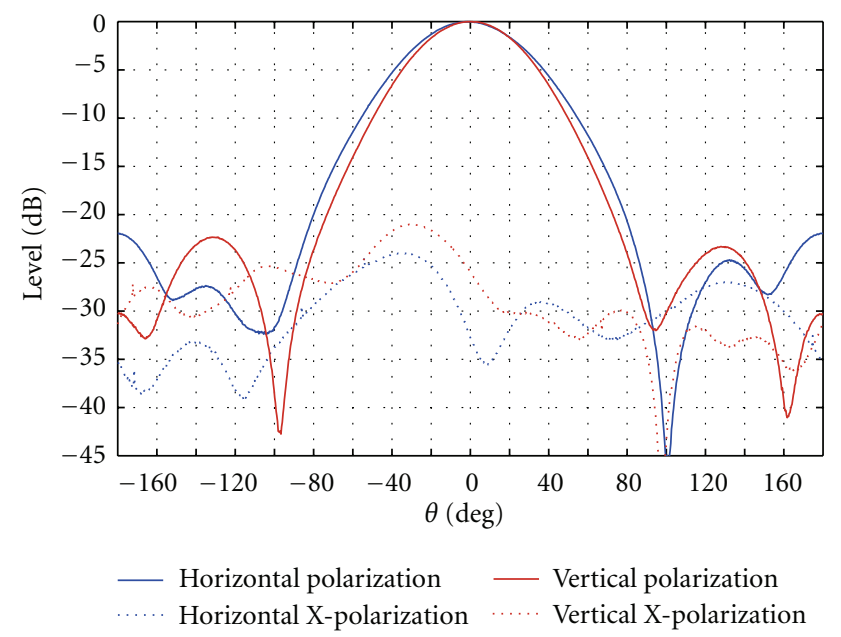

Figure 10: Measured pattern cut for horizontal (A dipoles) and vertical (B dipoles) polarization.

results showed very low AR for a similar feed [10]. Such feed with scaled dimensions operates at $1296 \mathrm{MHz}$ with a measured Axial Ratio better than $0.3 \mathrm{~dB}$. So the Axial Ratio $<0.3 \mathrm{~dB}$ (no choke) and $<0.6 \mathrm{~dB}$ (with choke) for the proposed $2320 \mathrm{MHz}$ feed section in the boresight direction can be expected.

4.4. Return Loss for $432 \mathrm{MHz}$ Band. Return loss for this band was measured behind the Wilkinson power divider to eliminate its influence on the measurement. Two MiniCircuits directional couplings, ZFDC-10-2-S, connected to the appropriate dipole were used for this measurement. The feed was excited by an Agilent E8257D signal generator. Output level was measured with a Wiltron 37347A spectrum

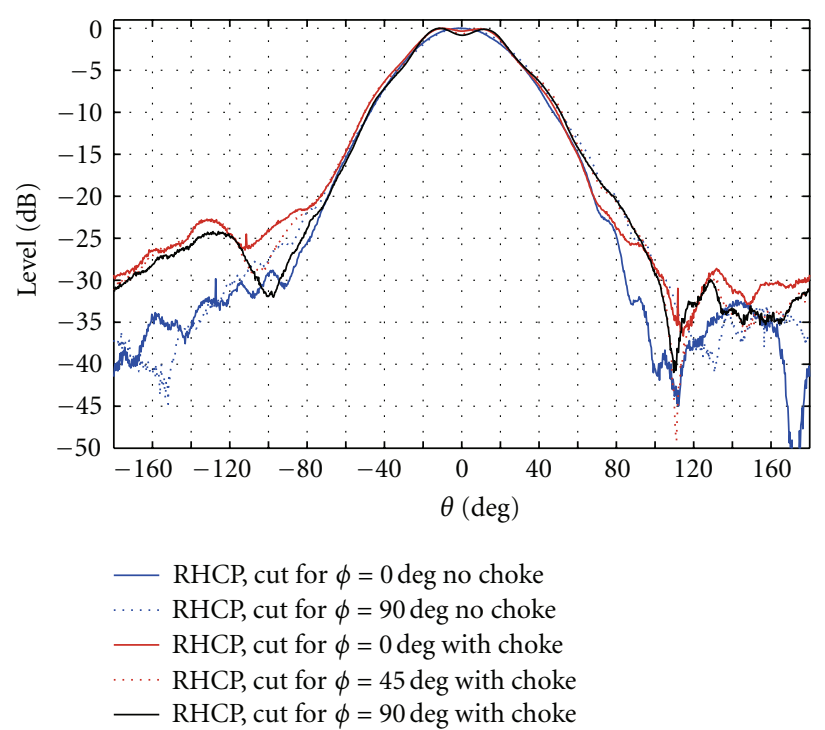

FIGURE 11: Measured pattern cut for RHC (RHC port excited) polarization without and with $432 \mathrm{MHz}$ section, working as a choke.

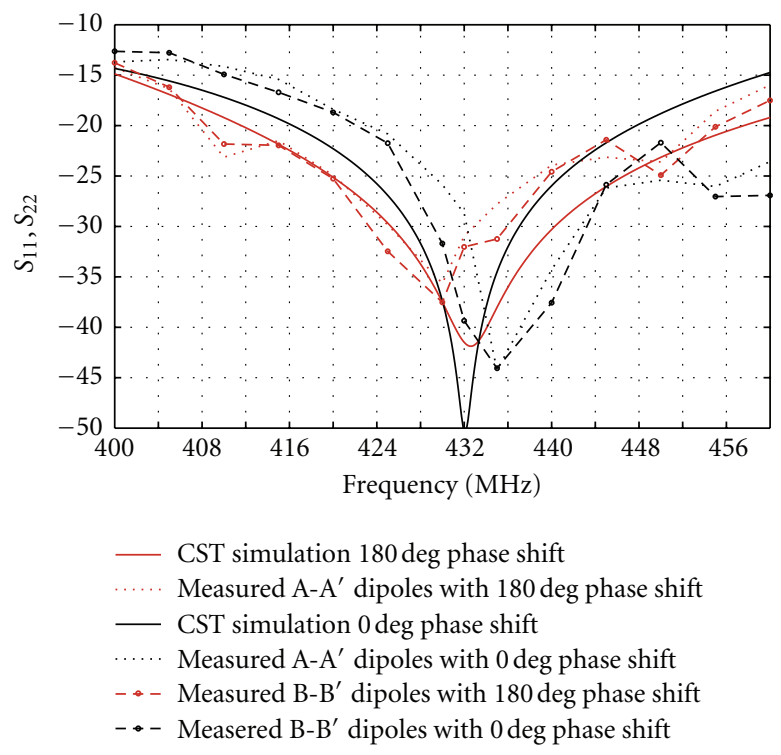

Figure 12: Measured and simulated return loss for $434 \mathrm{MHz}$ section.

analyzer. Calculated and measured results are shown in Figure 12. For each case, one set of respective dipoles (A$\mathrm{A}^{\prime}$ or $\mathrm{B}^{-\mathrm{B}^{\prime}}$, see Figure 3 ) was simultaneously excited with 0 or $180^{\circ}$ mutual phase-shift, realized by a different length of feeding cables.

4.5. Return Loss for $2320 \mathrm{MHz}$ Band. A Wiltron 37347A vector analyzer was used for these measurements. Very good impedance match throughout a wide bandwidth was observed (Figure 13); however, for EME, fractional bandwidth of only about $1 \%$ around $2320 \mathrm{MHz}$ is required. The differences between receiving $(\mathrm{Rx})$ and transmitting $(\mathrm{Tx})$ 


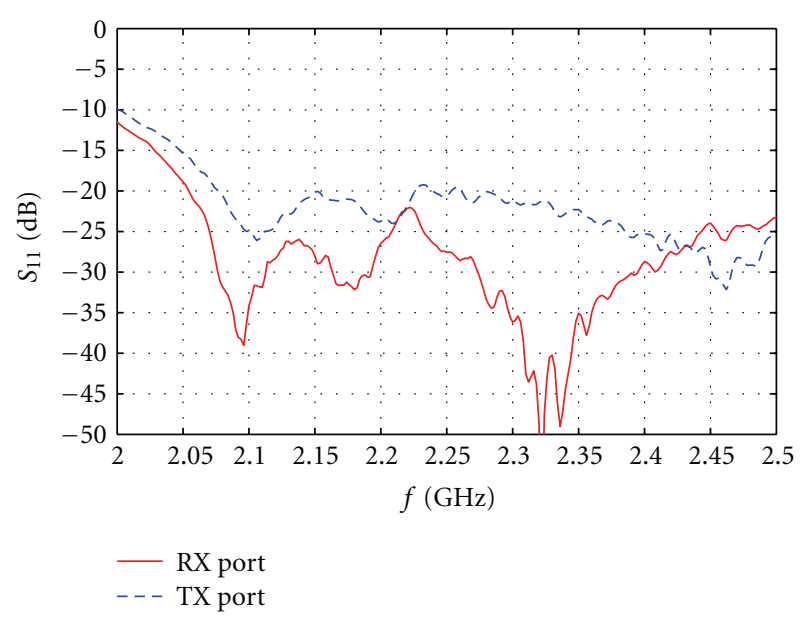

Figure 13: Measured return loss for the $2320 \mathrm{MHz}$ section.

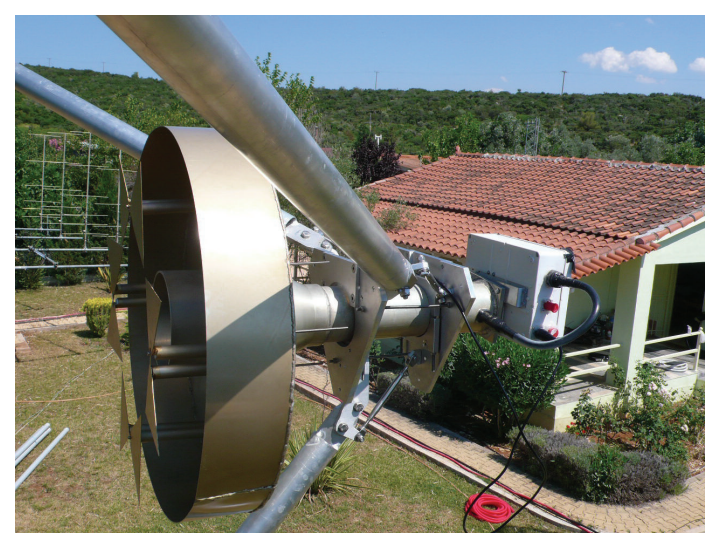

Figure 14: Prototype of the feed installed at the focus of a $6.4 \mathrm{~m}$ dish.

TABLE 1: Main design dimensions of the proposed prime-focus.

\begin{tabular}{lccc}
\hline Variable & $\begin{array}{c}\text { Dimension } \\
{[\mathrm{mm}]}\end{array}$ & $\begin{array}{c}\text { Dimension } \\
{\left[\lambda_{432}\right]}\end{array}$ & $\begin{array}{c}\text { Dimension } \\
{\left[\lambda_{2320}\right]}\end{array}$ \\
\hline$L$ & 216 & 0.311 & - \\
$W$ & 160 & 0.230 & - \\
$H D$ & 174 & 0.251 & - \\
$H R$ & 122 & - & 0.94 \\
$H$ & 123 & - & 0.95 \\
$D 1$ & 170 & - & 1.31 \\
$D 2$ & 660 & 0.95 & 5.11 \\
$D 3$ & 100 & - & 0.77 \\
$L 1$ & 175 & - & 1.35 \\
$L 2$ & 85 & - & 0.67 \\
$L 3$ & 407 & - & 3.15 \\
\hline
\end{tabular}

ports are attributed to dissimilar connector types at the ports. While the $\mathrm{Rx}$ port uses an $\mathrm{N}$ style connector, the $\mathrm{Tx}$ port employs a $7 / 16^{\prime \prime}$ DIN connector because of its power handling capability.

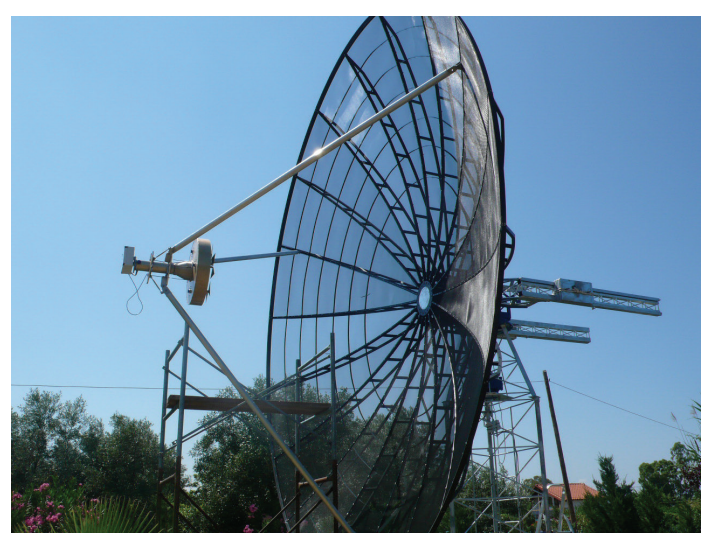

Figure 15: Prototype of the feed mounted on antenna during Sun noise measurements.

\section{Practical Experience}

Antenna Rx performance was tested using Sun versus cold sky comparisons on both bands, see Figures 14 and 15. On $432 \mathrm{MHz}$, a LNA with noise figure of $0.2 \mathrm{~dB}$ was used. On $2320 \mathrm{MHz}$, a LNA with noise figure of $0.45 \mathrm{~dB}$ was used. A solar flux level of $112 \mathrm{sfu}$ was present for all measurements.

An average Sun noise to cold sky ratio of $14 \mathrm{~dB}$ was achieved for the $432 \mathrm{MHz}$ band. A Sun noise to cold sky ratio of $17 \mathrm{~dB}$ was achieved for the $2320 \mathrm{MHz}$ band.

There exists further opportunities for performance improvement, mainly by reducing cable lengths between the feed connectors and the LNAs.

\section{Conclusion}

A compact, dual-band feed was designed for very low-noise applications and was successfully tested for Earth-MoonEarth operation. Antenna efficiency was evaluated by the EME Performance Calculator [18]. Reasonable values of $47 \%(40.5 \mathrm{dBi}) 2320 \mathrm{MHz}$ and $55 \%(26.64 \mathrm{dBi}) 432 \mathrm{MHz}$ based on Sun versus cold sky measurement were obtained. The lower efficiency on $2320 \mathrm{MHz}$ is attributed to slight deviations from the parabolic shape of the reflector. With butterfly-shaped dipoles used for $432 \mathrm{MHz}$ band, very good impedance matching was achieved over a wide frequency range and also the required parameters for power handling were satisfied.

\section{Acknowledgments}

The authors would like to thank Robert Valenta for discussions. This paper has been created under the COST IC1102 VISTA action and partially supported by the COST LD 12055 AMTAS (Advanced Modeling and Technologies for Antennas and Sensors).

\section{References}

[1] R. Galuscak, Advanced design of reflector based antennas [Ph.D. thesis], 2011, CTU-FEE. 
[2] Doug McArthur-VK3UM, "Dual $70 \mathrm{~cm}$ and $23 \mathrm{~cm}$ Dish Feed," DUBUS Magazine, 2006, http://www.vk3um.com/ VK3UMweb.pdf.

[3] Y. B. Karandikar and P. S. Kildal, "X-Ka dual band prime focus feed for satellite earth terminals," in Proceedings of the 3rd European Conference on Antennas and Propagation (EuCAP '09), pp. 3085-3089, March 2009.

[4] Online, http://www.mician.com/.

[5] Online, http://www.cst.com.

[6] H. E. King and J. L. Wong, "An experimental study of a balunfed open-sleeve dipole in front of a metallic reflector," IEEE Transactions on Antennas and Propagation, vol. 20, no. 2, pp. 201-204, 1972.

[7] T. A. Milligan, Modern Antenna Design, John Wiley \& Sons, New York, NY, USA, 2005.

[8] R. Galuscak, "Septum Feed Revisited," DUBUS, 2004.

[9] P. Hazdra, R. Galuscak, and M. Mazanek, "Optimalization of the septum polarizer feed for $1.296 \mathrm{GHz}$ EME station," in Proceedings of the European Conference on Antennas and Propagation (EuCAP'06), November 2006.

[10] R. Galuscak and P. Hazdra, "Prime-focus circular waveguide feed with septum polarization transformer," DUBUS, 2007.

[11] R. Behe and P. Brachat, "Compact duplexer-polarizer with semicircular waveguide," IEEE Transactions on Antennas and Propagation, vol. 39, no. 8, pp. 1222-1224, 1991.

[12] J. Bornemann, S. Amari, J. Uher, and R. Vahldieck, "Analysis and design of circular ridged waveguide components," IEEE Transactions on Microwave Theory and Techniques, vol. 47, no. 3, pp. 330-335, 1999.

[13] W. V. T. Rusch and P. D. Potter, Analysis of Reflector Antennas, Academic Press, New York, NY, USA, 1970.

[14] Ch. Yao, C. Ai-Xin, and S. Dong-Lin, "The optimization design of the Pickett Potter horn antenna for ka band," in Proceedings of the Asia-Pacific Symposium on Electromagnetic Compatibility and 19th International Zurich Symposium on Electromagnetic Compatibility (APEMC '08), pp. 626-629, Singapore, May 2008.

[15] M. J. Franco, "A high-performance dual-mode feed horn for parabolic reflectors with a stepped-septum polarizer in a circular waveuide," IEEE Antennas and Propagation Magazine, vol. 53, no. 3, pp. 142-146, 2011.

[16] K. Miyata and M. Suzuki, "Effects of choke-load position on radiation properties in double-choked small horn antennas," Electronics Letters, vol. 19, no. 9, pp. 329-330, 1983.

[17] Online, http://www.era.cz.

[18] Online, http://www.vk3um.com. 

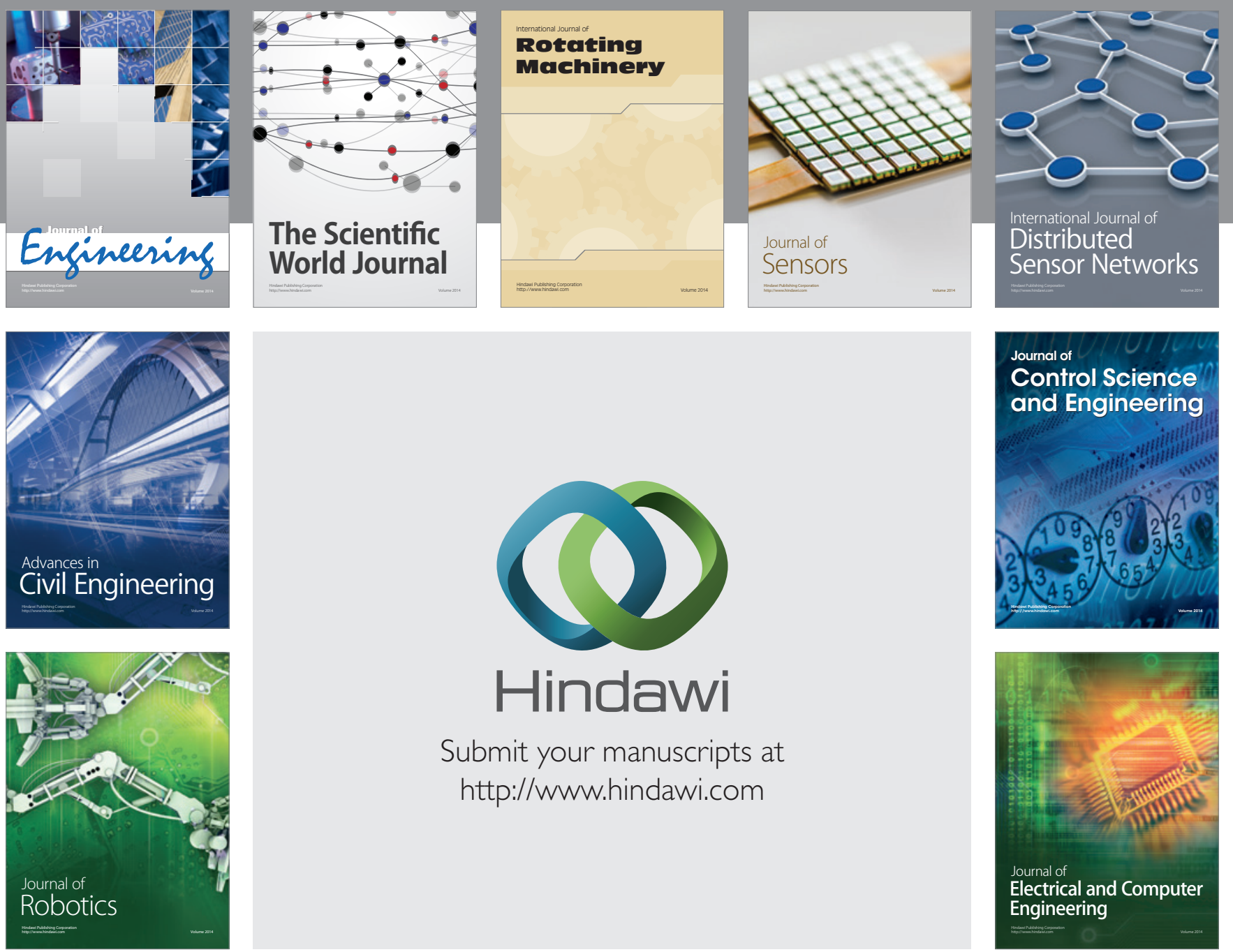

Submit your manuscripts at

http://www.hindawi.com
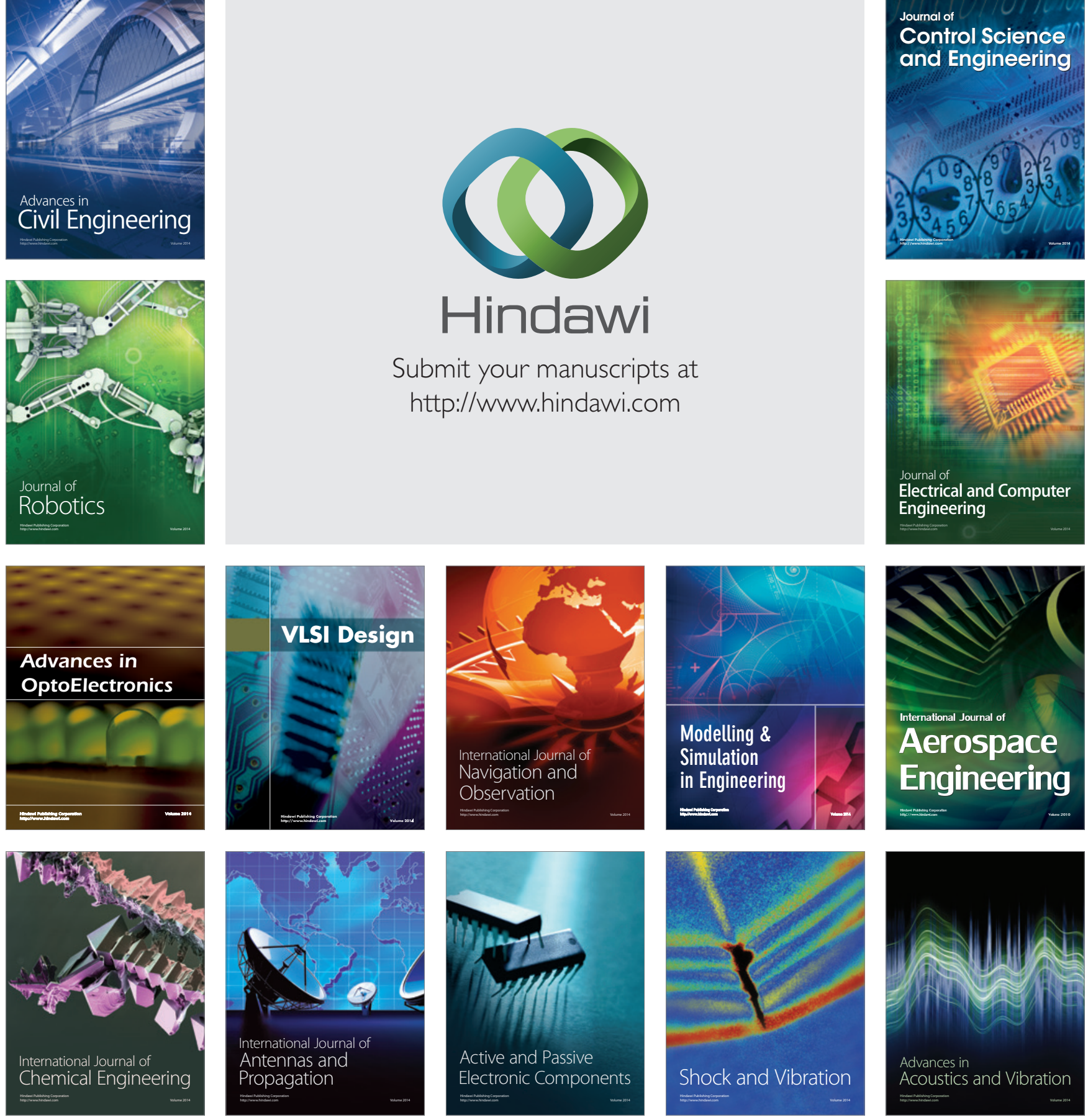